\title{
TEMPERATURE MEASUREMENT OF POLYMERS UNDER INTERMITTENT HEATING THROUGH USE OF THERMOCOUPLE AND ARDUINO ${ }^{\circledR}$ MICROCONTROLLER
}

\author{
F. dos A. Rodrigues, \\ K. F. A. Okada, \\ J. R. Ferreira-Oliveira, \\ and L. R. R. da Silva \\ Federal University of Uberlandia \\ School of Mechanical Engineering \\ João Naves de Ávila Avennue, 2121, Santa \\ Mônica District, Zip Code 38400902 \\ filipin_anjos@hotmail.com \\ kenji_okada09@hotmail.com \\ jose.ricardo@ufu.br \\ leonardo.rrs@gmail.com
}

Received: Jan 31, 2021

Revised: Feb 28, 2021

Accepted: Mar 01, 2021

\section{ABSTRACT}

The combination of relatively low production costs and a versatility make polymers one of the most used classes of engineering materials. The complexity of their chemical bounds, however, make the thermomechanical processing of these materials a challenge since thermal flux from manufacturing might significantly alter their properties. In this paper was evaluated the use of thermocouple with Arduino ${ }^{\circledR}$ compatible hardware for measurement and control of an intermittent heating system for processing of Nylon- 6 and polycarbonate thermoplastics. A $2^{2}$ factorial design was created for using K-type thermocouple for the two polymers at two different surface finishes obtained by sanding with mesh $\# 80$ and $\# 600$ abrasives. The results indicate that the Arduino interface has satisfactory processing capacity for monitoring heating cycles and temperature logging, making it possible to know how temperature variated and at what level it stabilized for the heating conditions presented. The difference in material specific heat capacity and thermal conductivity will affect the observed temperature profile. Roughness might present a considerable effect on the material heating since it is linked to the heat exchange area of the process.

Keywords: thermoplastics, thermocouple, Arduino ${ }^{\circledR}$ microcontroller, intermittent heating, MAX31855 module

\section{NOMENCLATURE}

$\mathrm{Rq}$ roughness parameter

Tss temperature at steady state

rT temperature increase in transient state

$\mathrm{Tr}$ reference temperature

\section{INTRODUCTION}

Polymers have been gaining increasing attention since the 20th century due to their versatility and cheap manufacturing. They are constituted of molecules with high molecular weight, usually containing carbon, oxygen and/or nitrogen in their molecular chains. Although they comprise a huge set of materials, they may be classified as elastomers, thermoplastics and thermosets, according to how their macromolecules behave as temperature changes (Osswald et. al., 2006). Thermoplastics have uncross-linked molecules in such way they flow viscously when heated but solidify as they cool. They present fair resistance at room temperature as solids and do not require much energy when processed by molding, finding several applications in packaging, transportation, and even in construction, since several thermoplastics possess tensile, impact and even heat resistance up to certain ranges.

Although in most applications polymers work well below their melting temperature, they are usually heated in manufacturing process to ease moldability and incorporation of fillers and pigments. It is important for engineers to know the temperature range that the polymer undergoes in these cases because it will affect process efficiency and final material characteristics. The first is because heating the material consumes energy but usually lowers the forces involved and accelerates reactions and mixing with additives. The second relates to different mechanical and physical properties in thermoplastics depending on how fast they cooled.

The temperature measurement and monitoring in these scenarios are accomplished by several ways whereas thermocouples are some of the most applicable choices. They are cheap, simple, robust, and cope with a wide range of temperatures (Oliveira et. al., 2020). However, they cannot operate on their own and need a system that not only converts their electric voltage signals to digital data but also calculates the corresponding temperature according to 
the voltage values and shows the information to the user. In line with the characteristics of simplicity, low cost and robustness, Arduino ${ }^{\circledR}$ compatible hardware and software were used in this work to acquire temperature data for a manufacturing process where a polymer surface experiments constant heating by hot air while being struck by an intermittent flow of compressed air at room temperature.

The dynamics of these interactions cause the material surface to be constantly heated and cooled in short cycles around temperatures high enough to changes bulk material properties. Although these cycles might cause instant temperature variations in polymer most outer surface, an inner surface will not experiment so great oscillations due to thermal damping by the material heat conductivity and specific heat capacity. Overall, if both hot and cold flow are maintained as explained, the material will heat up in a rate dependent on the thermal flow conditions up to a certain baseline temperature where it tends to stabilize around. In this work, the influence of material surface and polymer type were investigated regarding this rate of temperature rise and the baseline temperature attained when all other conditions were fixed. The preliminary results show that the acquisition system composed by thermocouple and Arduino ${ }^{\circledR}$ are adequate for monitoring the temperature, while the future complete results might indicate if there is any correlation and of how much between the material characteristics and surface roughness against the baseline temperature and heat rate.

\section{THERMOCOUPLES AND ARDUINO ${ }^{\circledR}$ CONTROL}

Thermocouples are the most common sensors for temperature measurements. Its working principle is based on the Seebeck effect. When two distinct homogenous materials are connected in a closed circuit and the two junctions experience different temperatures, electrons will diffuse across the circuit generating an electric potential difference. With a proper device to measure this small voltage, the signal can be correlated with the temperature difference between the two junctions (Oliveira et. al., 2020). The cold junction is kept away from heat sources, usually at room temperature, because it is the point of connection with the electronic devices that measure the small voltage and convert it to digital data. It is important to determine its temperature for compensating the voltage signal read by thermocouple. This is usually done through a thermistor or resistance temperature detector (RTD) built in the acquisition system as close to the cold junction as possible.

Regarding the acquisition system, Arduino ${ }^{\circledR}$ is an open-source electronic prototyping platform that allows users to create interactive electronic objects using a low-cost programmable logic microcontroller. Although they are not trustworthy and precise enough for monitoring and controlling sensitive industrial processes, they may be used for data logging over short time periods or in process that do not require an extremely precise monitoring of data (Vasconcelos Neto et. al., 2018). The compatible boards were chosen mostly due to its price and the constant risk of damaging other more sensitive equipment by dust and humidity around the manufacturing site.

Type K thermocouple was used, whose wires are made of Nickel-Chromium and Nickel-Aluminum alloys. They can be used from $-200{ }^{\circ} \mathrm{C}$ up to $1250{ }^{\circ} \mathrm{C}$ if the wire coatings do not degrade (Omega Engineering, 2015). An Arduino ${ }^{\circledR}$ compatible module with chip MAX31855 was employed, which has an inbuilt thermistor to automatically compensate for the cold junction temperature. The 14-bit module reads and converts analogic signal to digital data and sends it to the ATMEGA 2560 microcontroller through SPI communication, where temperature is calculated with $0.25{ }^{\circ} \mathrm{C}$ resolution. Their combination yields a sensitivity of about $41 \mu \mathrm{V} /{ }^{\circ} \mathrm{C}$ and their maximum error varies between $\pm 2{ }^{\circ} \mathrm{C}$ and $\pm 6{ }^{\circ} \mathrm{C}$ depending on the temperature interval being measured (Maxim Integrated, 2015). Compressed air line pressure was also registered through a piezoelectric pressure transducer from TMOEC. With operating range of 0 to $12 \mathrm{bar}$, it sends corresponding signals of $0.5 \mathrm{~V}$ to 4.5 $\mathrm{V}$ to the microcontroller, which calculates and register pressure values with a $1.5 \%$ precision.

\section{METHODOLOGY}

\section{Calibration of thermocouple and Arduino ${ }^{\circledR}$ module}

Every measuring system possess errors and therefore requires calibration. Especially in the case of thermocouples, an adjustment curve must be calculated to show the correspondence between real temperatures measured by more precise instruments and values indicated by thermocouple-based system. This way, a correction is applied to the measured data in order to reduce the offset error. For this, the measuring system was used firstly in a mix of distilled water and ice, and then in boiling distilled water. In the first case, data was acquired for 15 minutes after waiting $20 \mathrm{~min}$ for the mixture to be in equilibrium temperature. In the second, data was registered for 5 minutes, $10 \mathrm{~min}$ after boiling had begun. Measurements were performed at the city of Uberlandia-MG, about $850 \mathrm{~m}$ above sea level. Table 1 shows the average temperature and standard deviation values registered by the thermocouple and microcontroller system. A bulb thermometer with $0.2{ }^{\circ} \mathrm{C}$ resolution (up to $0.1{ }^{\circ} \mathrm{C}$ through interpolation) and range of 0 to $200{ }^{\circ} \mathrm{C}$ was employed. The thermometer readings were considered as the actual correct values, and they did not vary during thermocouple data acquisition. 
Table 1. Comparison of temperatures obtained by bulb thermometer (BT) and thermocouple system (TS)

\begin{tabular}{|c|c|c|}
\hline BT $\left({ }^{\circ} \mathbf{C}\right)$ & TS $\left({ }^{\circ} \mathbf{C}\right)$ & $\begin{array}{c}\text { Deviation in } \\
\text { Kelvin (\%) }\end{array}$ \\
\hline 0.30 & 1.72 & -0.52 \\
\hline 96.20 & 95.61 & 0.16 \\
\hline
\end{tabular}

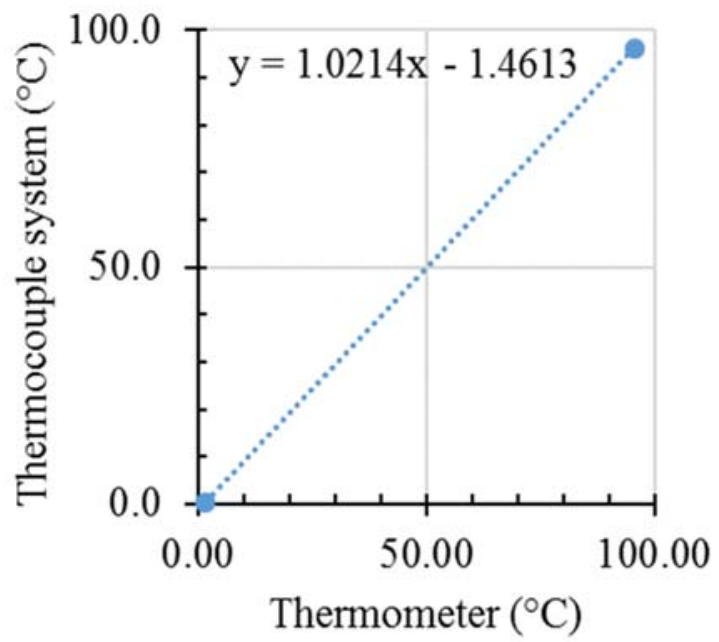

Figure 1. Thermocouple temperature calibration in distilled water at fusion and boiling.

The equation resultant of linear regression shown in Fig. 1 is adequate for correcting the measured temperature during the actual manufacturing process, since the temperature variation is within the calibrated values and type $\mathrm{K}$ thermocouple is linear in this range (Nicholas and White, 2001).

\section{Design of experiments}

The materials used were Nylon 6 (Ny) and polycarbonate (PC), cut in samples of $30 \times 20 \times 4 \mathrm{~mm}$. For each material, one sample was grinded with mesh 80 sandpaper and the other was grinded with 600 sandpaper, ensuring similar surfaces and roughness. Table 2 shows the average and standard deviation for five measurements of $\mathrm{Rq}$ in each sample.

Distinct polymers have different thermal properties such as specific heat capacity and thermal conductivity, which vary greatly with temperature as shown in Osswald et. al. (2006). They will affect heat distribution, maximum temperature (baseline temperature after stabilization) and rate of increase in temperature. This are important parameters since the thermal flux on the polymer might modify sharply its mechanical and physical properties.
Table 2. Roughness parameters (values in $\mu \mathrm{m}$ ) for the grinded samples (average-AV and standard deviation-STD)

\begin{tabular}{|c|c|c|c|c|}
\hline \multirow{2}{*}{ Material } & \multirow{2}{*}{ Mesh } & \multirow{2}{*}{ Cut-off } & \multicolumn{2}{|c|}{ Rq } \\
\cline { 4 - 5 } & & & AV & STD \\
\hline PA & 80 & $2.5 \mathrm{~mm}$ & 7.61 & 1.06 \\
\hline PA & 600 & $0.8 \mathrm{~mm}$ & 0.31 & 0.04 \\
\hline PC & 80 & $2.5 \mathrm{~mm}$ & 5.49 & 0.40 \\
\hline PC & 600 & $0.8 \mathrm{~mm}$ & 0.73 & 0.13 \\
\hline
\end{tabular}

This way, a factorial design of experiments of the type $2^{2}$ is attained, considering the two different roughness and two materials as input variables. The output will be the baseline temperature and rate of temperature rise to steady state, starting observation when temperature reaches $50{ }^{\circ} \mathrm{C}$ and acquiring data over 5 minutes. It is important to highlight that the heat flux is not constant and therefore the term "steady state" is not appropriate, but it will be used to refer to the condition in which.

\section{EXPERIMENTS}

The hot air source used was a heat blower gun BOSCH GHG630DE with up to $2000 \mathrm{~W}$ and temperature adjustment through electronic thermostat. Gun temperature was fixed and was constantly hitting the sample. Compressed air line pressure was regulated at about 2 bar in regulator-filter set and was directed to the sample by a jetting pistol. The compressed air was released in a cyclic manner, being automatically opened and closed in regular determined times. When opened, the compressed air jet dislocated the smaller hot air flow and absorbed heat from the sample.

Thermocouple, module, pressure transducer and microcontroller were connected to a protoboard. The Arduino ${ }^{\circledR}$ based PLmC was connected to a laptop via USB cable for data logging in text file at rate of $5 \mathrm{~Hz}$. In this configuration, the system is subject to oscillations resultant from electromagnetic fields generated by near machines, WiFi signals or others. Although there might be other causes, this might explain the noise observed, which is present even in temperatures measured in the isothermal mix of water and ice.

Figure 3 shows the equipment, while Figure 4 shows the schematics of the thermocouple fixed to sample with epoxy resin. Since this device measures temperature by contact, it is particularly important to position it similarly during all the experiments. In this configuration, they are probing the temperature of the sample at $1 \mathrm{~mm}$ below the surface hit by hot air. 
Meanwhile, the other side of the sample rests on a stainless-steel plate holder.
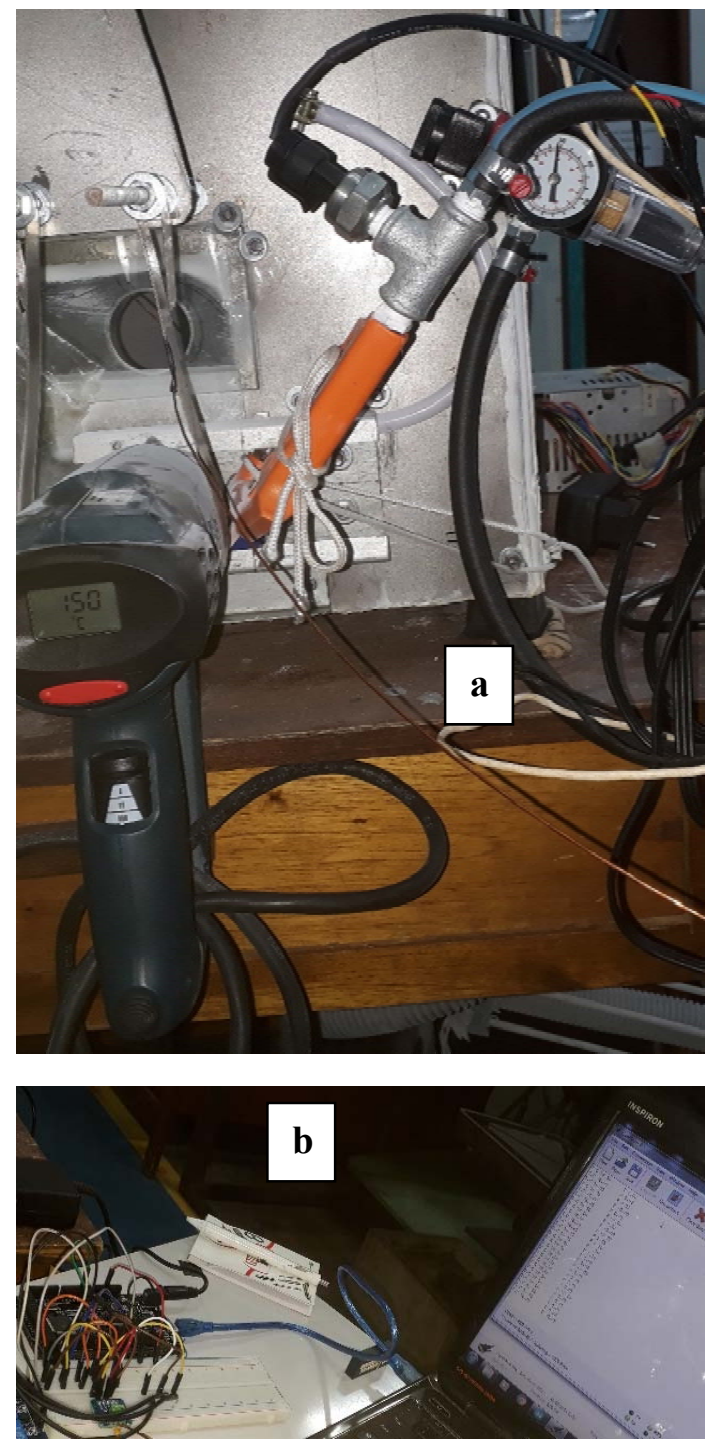

Figure 3. a) Heat blower gun and compressed air pistol. b) Arduino ${ }^{\circledR}$ based PLmC, protoboard, USB and laptop.

\section{RESULTS AND DISCUSSION}

Figure 5 shows the temperature and pressure data obtained during 5 minutes for surface of polycarbonate mesh 600 after sample reached $50{ }^{\circ} \mathrm{C}$. It is possible to see stabilization around level of $77^{\circ} \mathrm{C}$. Part of the observed high frequency variation can be associated to the electromagnetic noise commented earlier. But, as compressed air hits the sample, its temperature is also expected to vary at about the same frequency of the blown compressed air, due to the corresponding change in heat flux. Inherently, the thermal capacity of the polymer and the distance from thermocouple to polymer surface dampens a and delays the heat flux arriving at the thermocouple.

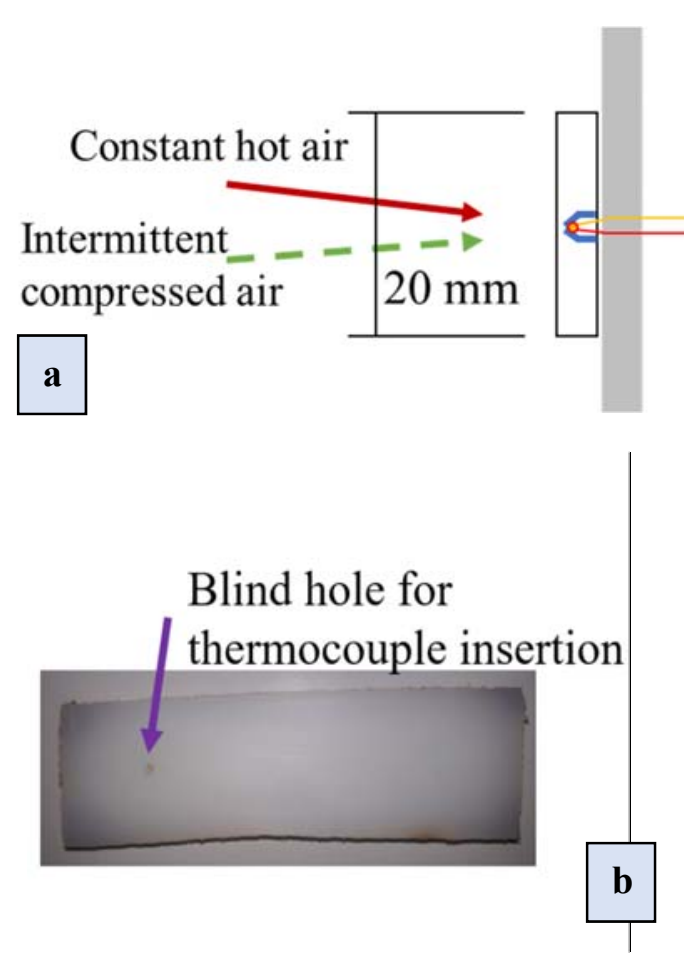

Figure 4. a) Schematics of hole for thermocouple positioning and b) sample placement.

The most important information from these graphs is the baseline temperature at steady state Tss $\left({ }^{\circ} \mathrm{C}\right)$ and rate of temperature increase in transient state $\mathrm{rT}\left({ }^{\circ} \mathrm{C} / \mathrm{s}\right)$. The analysis of the curve was carried by fixing a temperature above which the system is considered to have entered steady state. This temperature was set as $95 \%$ of the highest observed value during the 5 minutes. Since the signal varies considerably, firstly an average moving filter was applied to smoothen the curve as shown in Fig. 6. This way a better separation of the transient regime is achieved. For this material and surface, the calculated reference temperature $\mathrm{Tr}$ was $74.06^{\circ} \mathrm{C}$, first reached at $2 \mathrm{~min}$ and $43 \mathrm{~s}$.

After completing the experiments, a statistical analysis can be done to verify if the change in the output is significantly related to material properties or surface conditions.

Table 3 shows the results for all samples, for which analysis of variance was carried. The baseline temperature for Nylon 6 was slightly higher than for polycarbonate. Although the higher specific heat for Nylon 6 would lead to a lower temperature considering the same heat flux, this could be related to the higher thermal conductivity that makes that more heat arrives at the point where thermocouple is fixed.

Nevertheless, this cannot be affirmed because the analysis of variance showed there is no significant difference for the Tss $\left({ }^{\circ} \mathrm{C}\right)$ between the two materials. 


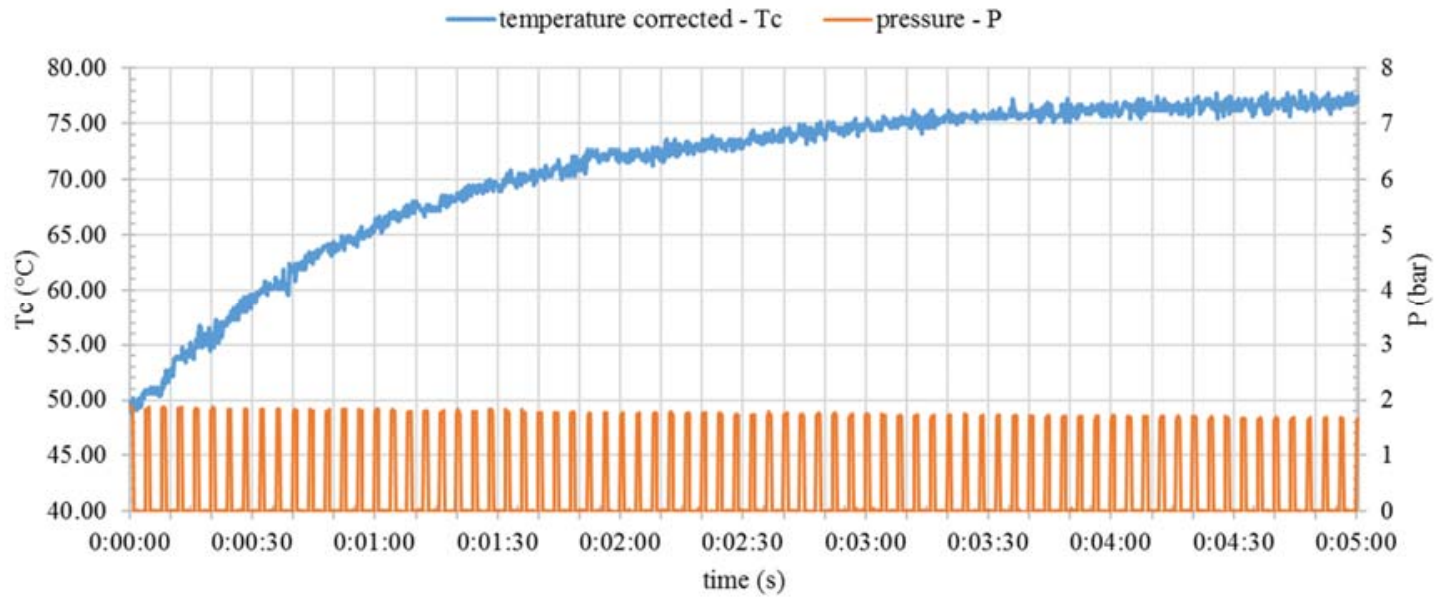

Figure 5. Temperature corrected by linear regression from Fig. 1 and pressure data during intermittent heating cycles.

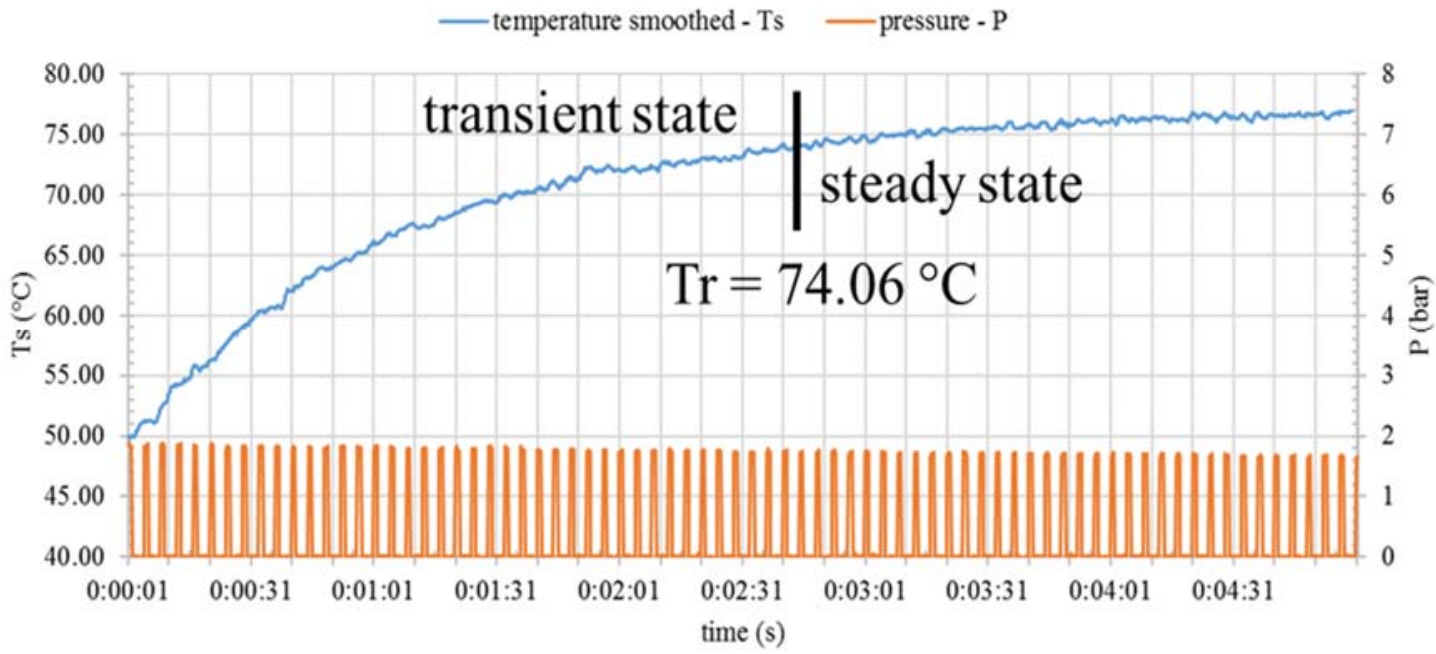

Figure 6. Temperature smoothened by an average moving filter of $\mathrm{N}=7$.

Regarding Rq, it did not have any clear effect on the baseline temperature. Although a greater roughness could favor heat exchange due to increased surface area, this effect was not perceived for the tested conditions, neither in the steady state temperature nor in the rate of increase during transient state.

Table 3. Baseline temperature and rate of increase for the two materials and two surface conditions

\begin{tabular}{|c|c|c|c|}
\hline Material & Mesh & Tss $\left({ }^{\circ} \mathbf{C}\right)$ & rT $\left({ }^{\circ} \mathbf{C}\right)$ \\
\hline PC & 600 & 73,89 & 0.0339 \\
\hline PC & 80 & 74,68 & 0.0311 \\
\hline PA & 600 & 76.21 & 0.0518 \\
\hline PA & 80 & 75,36 & 0.0547 \\
\hline
\end{tabular}

It is evident that the rate of temperature increases up to steady state was higher for Nylon 6. According to the analysis of variance, there was a significant higher rate for this material considering a significance level of $10 \%$. This is likely due to the higher thermal conductivity, which is about $10 \%$ higher than that of polycarbonate. But again, the $\mathrm{cp}$ from Nylon 6 is almost $30 \%$ higher than for polycarbonate, which would lead to a lower temperature considering the same heat flux for the two samples. This means that for the conditions essayed the effect of $\mathrm{K}$ superseded the effect of specific heat, probably because of the high thermal load provided by the heat gun in comparison with the low heat capacity from the samples since they are very small. 


\section{CONCLUSIONS}

Temperature measurements with thermocouple and Arduino compatible hardware were carried in polymers subject to intermittent heating from a manufacturing process. To simulate this condition, a heat gun and compressed air were used to heat and cool down the polymer surface in a cyclic manner. The thermocouple was positioned $1 \mathrm{~mm}$ below the surface and captured the temperature evolution, from which the following conclusions can be drawn:

- Although there was some noise in the signal, the data acquisition system based on Arduino proved to be a reliable and very cost efficient acquisition system specially when applied to situations that do not require very precise monitoring and control of process temperature.

- The position of the thermocouple creates a thermal dampening effect in which the flow temperature variations are not sensed by the thermocouple right way. Furthermore, any possible fluctuation due to the varying thermal load is not easily distinguishable from the noise.

- The air came out of the heat gun at a temperature of almost $150{ }^{\circ} \mathrm{C}$, the maximum baseline temperature the polymers reached was about $76{ }^{\circ} \mathrm{C}$. Although the distance of samples is enough to cool down the hot air by some degrees, this also shows that even a small layer of polymer shielding the thermocouple creates a considerable heat resistance.

- According to the analysis of variance the temperature reached by both polymers after 5 min of intermittent heating had no significant difference, which indicates it has more to do with the air temperature and flow then with the materials used, which do not differ substantially in its thermal properties.

- There was a significant higher rate of increase in temperature for Nylon 6 during the transient state, indicating that the slightly better conductivity of this material allowed the heat to diffuse to the thermocouple more efficiently. This shows that this thermal property was the most important in our work, probably because of the small size of the samples.

\section{ACKNOWLEDGEMENTS}

The authors thanks CNPq and CAPES for their support in the form of graduate scholarhips.

\section{REFERENCES}

Maxim Integrated, 2015. Cold-Junction Compensated Thermocouple-to-Digital Converter. Maxim Integrated, 5th ed.

Nicholas, J. V. and White, D. R., 2001. Traceable Temperatures: An Introduction to Temperature Measurement and Calibration. John Wiley \& Sons, New Jersey, 2nd ed.

Oliveira, J. R. F., de Lucena, L. R. R., dos Reis, R. P. B., de Araújo, C. J., Bezerra Filho, C. R., Arencibia, R. V., 2020. "Uncertainty quantification through use of the Monte Carlos method in a onedimensional heat conduction experiment". International Journal of Thermophysics, awaiting publishing.

Omega Engineering, 2015. Manual de Referência Técnica de Temperatura. Omega Engineering

Osswald, T. A., Baur, E., Brinkmann, S., Oberbach, K., Schmachtenberg, E., 2006. International plastics handbook: the resource for plastics engineers. Hanser Publishers, Munich, 1st ed.

Vasconelos Neto, W., Soares, J. L. L., Martins, S. T. A. A., Oliveira, G. S. Q., Freire, W. A. C., Rocha, H. M. Z., 2018. "Acquisition of thermocouple data by Arduino ${ }^{\circledR}$ microcontrollers". In Proceedings of the 17th Brazilian Congress of Thermal Sciences and Engineering - ENCIT 2018. Águas de Lindóia, Brazil. 